\title{
Television Series Review
}

\author{
Review of Couples Therapy (2012-2015). USA: Irwin Entertainment.
}

Michael McAndrew, M.A. LPCC ${ }^{1}$

Colorado Analytic Forum

"Psychoanalysis, according to Jacques Lacan, is founded in a principle announced as:
"There is no sexual relation".
It's corollary, or another way to phrase it is: "Jouissance is impossible".
Josefina Ayezera, "There is no sexual relation." (2011)

Showtime's Couples Therapy (2019-2021) has done something very few shows have done well-showcase real therapeutic treatment on television. The advent of "prestige tv" has led to a proliferation of programs which show the therapeutic relationship in hi definition between protagonists and their therapists, such as HBO's The Sopranos (1999-2007), and the recently revived In Treatment (2008-2010, 2021). Prior to this the "real" therapy seen on television was limited to the so-called "reality television" trend that gave us the wildly popular Intervention on A\&E (2005-ongoing) and the seedier Celebrity Rehab with Dr. Drew (2008-2012).

Couples Therapy, (directed by various, though primarily overseen by director Josh Kriegman his co-producer Elyse Steinberg) is a documentary series depicting the practice of New York City based psychologist and psychoanalyst Dr. Olga Guralnik, as she works with various couples inside and outside (more on that later) her set-as-office specifically designed by the producers to allow multiple angles of the couples, and their analyst. Much as the name implies, the first and second season depict several couples over the course of their treatments. Where Couples Therapy really shines, however, is in the breadth of the couples; not just necessarily limited to the stereotype of the "worried well" neurotic New Yorkers.

Many previous reviewers of the show have zeroed in on husband-and-wife Annie and Mau, who, at twenty-three years of marriage have been married the longest of any of the couples on the show. Mau is often depicted in the documentary as the perfunctory villain of both the documentary and this particular made for Instagram couple, seemingly by his own choice, as well as the directors. "Someone has to be the villain." (Couples Therapy, 2019). He does this job more than ably, to the detriment of his long-suffering partner, and to Dr. Guralnik's patience (and the viewers).

Perhaps the most compelling (and realistic) couple of season one, however, are Lauren and her partner Sam. As a practicing Lacanian psychoanalyst in formation, I am familiar with the welltrod idea that psychodynamic and psychoanalytic based therapies in the United States are outdated, unhelpful, take too long, and are mostly for well heeled, white, neurotics. Yet, Guralnik's approach is based fundamentally in these ideas; Dr. Guralnik is a faculty member at the NYU Postdoctoral Institute for Psychoanalysis, as well as the editorial board of Psychoanalytic Dialogues and of Studies in Gender \& Sexuality. Guralnik positions herself well against this stereotype, with thoughtful, sensitive interventions that cut to the heart of the issues between Sam and Lauren. Sam and Lauren, are, respectively, a couple made up of a nonbinary partner and a transwoman who struggle with both "traditional issues" of couples in

${ }^{1}$ Correspondence concerning this article should be addresses to Michael McAndrew. Email: mcandrew.mr@gmail.com

Language and Psychoanalysis, 2021, 10 (1), 53-54.

http://dx.doi.org/10.7565/landp.v10i.5705 
couples therapy (division of household labor, financial struggles) but also with the demand and desire to conceive a child, pitting them against the medical and psychotherapeutic discourse which has traditionally not been kind or gentle to anyone, much less already marginalized people. It is through their sessions in Couples Therapy that we can see just how much these two are up against, and present a struggle not generally seen in America's living rooms.

It is in this depiction of a reality more reflective of the current age that Couples Therapy really shines, and speaks to what psychoanalysis can offer people, as subjects in analysis and as the two of a couple. Couples Therapy was already wildly successful in its first season, and a second was subsequently planned; these plans (lie the plans of many) were subsequently altered by the "couple" of the pandemic COVID-19 and the ongoing protests over the racialized terror of police killings of black and brown people in the United States.

A subsequent Couples Therapy: The COVID special followed season one and depicted the many issues that faced analysts and their patients during the pandemic of our COVID year: Issues with accessibility and use of technology of teletherapy devices and software during the pandemic, job loss, loss of income, and, in the case of our couples, having to spend A LOT of time with each other-for good and bad. We also get a peek behind the "opaque mirror" of the analyst, as we see Dr. Guralnik attempts to (more or less successfully) conduct ZOOM sessions in a spare room in her house that is a major departure from her well-appointed office, while being a full-time parent. Given the amount of time I spent as the occupant of the former guest room of my apartment conducting phone analysis, I can relate-particularly as one of my patient's sessions was "cut" short by a sudden enthusiastic leak in my ceiling from an exploded boiler on the roof of my building.

A boiler exploding is also present in the COVID special, in the sense that cities in the United States ignited overnight after the killing of George Floyd by police officers in Minneapolis in the summer of 2020. Many of Dr. Guralnik's patients are mixed race couples, or people of color; and during that hot summer, many things reached a boiling point for people-within their homes, within the consulting room, and in the streets. We see many of her patients tired-tired of the dispositief of state sponsored terrorism, tired of having to justify their existence, and tired of having to explain and justify their desires to white figures of authority, even to their therapists. It is during this time that Dr. Guralnik seeks control analysis with Dr. Kirkland Vaughans. Dr. Vaughans, a psychoanalyst and psychologist who is African American, has written extensively on the trauma facing black men and boys in the U.S., as well as a member and faculty of a number of psychoanalytic institutes. These scenes of control are vital to show how an analyst must examine their own deafness for a certain subject; particularly when the analyst is white and the analysands black or brown. These scenes also resonated for me; as I was, at the time, back in my office in uptown Denver, not far from where the protests in my city were taking place. Like Dr. Guralnik, many of my own analysands are people of color, and the content of their sessions often dealt with life, death, and desire in the face of an other who doesn't even consider you worthy of personhood.

In short, Couples Therapy is a show worth watching, for those on the couch, or sitting behind or across from it; and, though I myself do not practice couples therapy, I will certainly continue to watch, and learn from the vital issues Couples Therapy raises. 